INFORMAL LOGIC

XI.2, Spring 1989

\title{
Critical Thinking as Applied Epistemology: Relocating Critical Thinking in the Philosophical Landscape
}

\author{
MARK E. BATTERSBY Capilano College
}

\section{Introduction}

One of the most important developments in contemporary philosophy has been the interest in applying philosophy to contemporary issues. This occurred first on an ad hoc basis as philosophical reasoning was brought to bear on various moral problems, such as abortion and triage. But more significantly, it has involved the creation of applied disciplines such as applied ethics (and sub-disciplines such as professional ethics) and Critical Thinking or informal logic. ' While most philosophers would probably not question my claim concerning the importance of developments in applied ethics, they might well question the claim as it applies to informal logic.

But I think that this would be a mistake. In this paper I will argue that critical thinking's relationship to philosophy could well be as productive of philosophical insight as is applied ethics, and, as a result, critical thinking deserves the same philosophical attention as that accorded applied ethics.

"Informal logic" is the name commonly used in philosophical circles to describe critical thinking, but it tends to obscure the relationship of critical thinking to philosophy; critical thinking is not a "casual" relative of logic, as the name suggests, but, rather, it is a significant effort to apply many of the insights of philosophy and particularly of epistemology to common questions about what we should believe. What makes Critical Thinking "critical" is the often negative impact on belief that results from the application of epistemological norms to common problems and judgements. Because it is epistemological norms and not rules of logic that constitute the philosophical core of critical thinking, it is unfortunate that this activity has been called and, therefore, misunderstood as informal logic. A better nomenclature would be "applied epistemology", suggesting as it does the right philosophical heritage and the parallel with applied ethics. Indeed, it is reasonable to expect that critical thinking will generate as many interesting problems for epistemology as applied ethics has done for ethics.

There is no novelty in the claim that the theoretical core of critical thinking should be thought of as epistemology; an excellent paper by Harvey Siegel (1985) makes this case quite eloquently, and McPeck (1981) has made a similar point. The argument is very simple. Most of the claims that critical thinkers wish to examine are not deductively supported by their evidence, but are supported by evidence that "warrants" or justifies the belief. The crucial challenge for critical thinkers is to articulate the norms which can be used to justify well supported beliefs and criticize those that are not. While I elaborate this argument slightly, I am primarily concerned to bring to the attention of philosophers the value that the study of critical thinking has for epistemology. I do this by pressing the analogy of applied ethics, and illustrating the significant epistemological difficulties that critical thinking has already revealed, as, for example, the problems surrounding the appeal to authority.

Critical thinking's failure to attract appropriate attention from the discipline of 
philosophy is due I think partly to its history and partly to its novelty. Dealing first with its history...

Critical thinking began primarily as a "teaching discipline." Howard Kahane, who can be given large credit for initiating this effort, has explained how he was pushed by student demands for relevance that characterized the sixties to create an informal logic course. To many in philosophy, informal logic remains something either to be celebrated or endured in the curriculum, as a hold over from the sixties and as a boost to student enrollment in the eighties. Because of the history and role that introductory critical thinking courses play, philosophers view the course as a service course, as essentially remedial, yet rarely as a subject with interesting problems worthy of study and research.

I think this is the wrong attitude. Applied ethics had the same "sixties" origins, but has now grown into a discipline with numerous journals, and sub-disciplines. It has done so because those who began seriously to "apply" such ethical understanding as they thought philosophy possessed discovered that their theoretical understanding was not up to the complexity of many real life situations. As a result, there was a need for theoretical development which gave central place to the processes and problems of application, the study of which gradually took on a life of its own.

Important effects of this awareness have been the renewed emphasis on rights in ethical and political literature, increased skepticism about the value of utilitarianism to solve ethical problems despite its selfproclaimed practicality, and a general awareness that much of the difficulty in applying ethical norms comes in interpretation of the norms during application. More generally, the actual effort to resolve pressing moral dilemmas, or at least to provide guidance for approaching moral problems, has led to a deeper understanding of moral reasoning and a revitalization of ethical theory as exemplified in such journals as Philosophy and Public Affairs.

Much the same may be expected from critical thinking. Not only do striking parallels exist between the relationship that critical thinking bears to epistemo'ogy and that which applied ethics bears to traditional ethical theory, but there are already problems that have been encountered by critical thinking instructors that could have profound impact on epistemology. The discussion of these problems will provide the second ground for my claim.

To develop my claims about the parallels between applied ethics and critical thinking, I must first give a more detailed account of what I see as the situation in ethics. Subsequently, I will show how this categorization of ethics can be applied to epistemology to illuminate the relationship between critical thinking and traditional epistemology.

\section{The Parallel and its Implication for Critical Thinking}

\section{Ethics}

Ethics can be divided into three subareas (exhibiting the traditional philosophical enthusiasm for tripartite distinctions): meta-ethics, normative or theoretical ethics, and applied ethics. Courses and texts are often divided up this way: such a subdivision of ethics is relatively uncontroversial.

1.1 Meta-ethics. Beyond the analysis of basic ethical concepts, meta-ethics is concerned with the nature and foundation of ethical knowledge, particularly with the question of whether there is any ethical knowledge. ${ }^{2}$ The difficulties in establishing a secure basis for ethical claims has led many philosophers and even more first year students to conclude that some kind of skepticism or relativism is the only reasonable position. The arguments for and against 
skepticism and relativism, Naturalism and Intuitionism, and arguments generally about the nature of ethical discourse fall under meta-ethics.

1.2 Normative or Theoretical Ethics. Normative ethics, in contrast to meta-ethics, assumes that there is some ethical knowledge to be acquired (or at least that there are better and worse answers to ethical questions) and that this knowledge is usually articulated in a principle or fundamental set of principles or norms. The job of the philosopher in this area is to find these principles, articulate them, and show that these are the principles that any ethically thoughtful person should accept.

Normative ethics has tended to bifurcate into two major approaches: consequentialism and the deontologism. Consequentialism, as its name implies, holds that the rightness or wrongness of acts is wholly a function of their consequences. Deontologism (deon (Gr.) = duty) denies this claim insisting that some acts are right or wrong independent of their consequences. The principle representatives of each approach are Utilitarianism and Kantianism. Both schools have tried to show that this approach to ethical reasoning yields the correct outcome in actual moral situations. However, their main emphasis has been to argue about imaginary problems and thought experiments-some of them thoroughly bizarre. A more practical approach has been taken by John Rawls. His recent effort to ground ethical norms in a decision procedure using the "veil of ignorance" is an excellent example of normative ethics. ${ }^{3}$

1.3 Applied Ethics. While philosophers have obviously been concerned over the centuries with applying ethical theories to practical issues, the appearance of a subdiscipline devoted to this endeavor is of recent vintage.

The original goal of applied ethics was to use the insights and principles of nor- mative ethics to illuminate or even resolve issues of contemporary moral debate such as abortion and the allocation of scarce medical resources. But while this was the intent of applied ethics, in practice the inadequacy of many traditional moral theories and the difficulties in their interpretation has resulted in the development of new approaches which are grounded in the problems being studied. Therefore, the distinction between applied ethics and normative ethics is not so much a conceptual one as is the distinction between meta-ethics and normative ethics, but rather one of focus. Applied ethics focuses first on the ethical problem and only then on the ethical theory. The question for applied ethics is first, what is the morally correct action in response to this sort of situation? and then what are the correct principles of ethical theory?

Of course many great ethicists have written about everyday problems. As, for example, did Kant in his Lectures, or Mill in his chapter on "Applications" in On Liberty. In doing so, they were engaged in applied ethics, but they differed from contemporary applied ethicists in that these efforts were afterthoughts, rather than their central concern.

Take the problem of abortion. One could start out with a theory about the universal right to life and then puzzle over how to apply it to a fetus. Or one could start, as various thinkers have, with the problem of trying to discern what the morally relevant differences are (if any) between a fetus, a dying violinist, a human vegetable, and a zygote. ${ }^{4}$ This "problem first" approach is both exciting and illuminating. One of the consequences of this approach has been an increased awareness of the problem of interpretation of ethical norms in actual application. One may expect that new normative theories might emerge from this effort; though they may fall roughly into one of the normative camps, the emphasis on real problems assures that the theories will be tied to the rich factual base of ordinary and extraordinary problems of everyday life. 
It is not so much the move to apply philosophy that is exciting about applied ethics, but rather the feedback that these attempted applications generate. By sensitizing us to the difficulty of interpretation, and the inadequacy of existing normative theories, and by placing philosophers in positions where decisions must be made, applied ethics has inspired a renaissance in ethical reflection.

One further distinction should be mentioned. There is ethics even beyond applied ethical theory, that is, there is being ethical. I do not see the making of individual ethical judgements about, for example, whether to have an abortion in a particular case, as being applied ethics. These are cases of applying ethics, yes: but not an event in the field of applied ethics. On the other hand, to the extent that someone criticizes an ethical decision on the basis of the misapplication of ethical norms (as opposed to factual and logical error), this seems to me an activity inside, though near the border of, applied ethics. This distinction will become important when I go on to discuss applied epistemology.

How does the above division of ethics compare to an appropriate division in epistemology?

\section{Epistemology}

There is not a well established trichotomy of this in epistemology, but I have one to propose, one directly analogous to that of ethics. ${ }^{5}$

2.1 Meta-Epistemology. First, there is meta-epistemology. This is what most philosophers think of under the general term of "epistemology': the study of the central concepts of knowledge and the foundations of the theory of knowledge. ${ }^{6}$ Metaepistemology attends primarily to epistemic discourse and it, too, can lead to skepticism about the possibility of knowledge. It has as its goals the analysis of epistemological discourse as illustrated by the continuing efforts to discover the missing ingredients in the traditional analysis of knowledge as justified, true belief (illustrated in the puzzles of Gettier). Why it has not been called meta-epistemology is not clear to me. This failure has tended to create the illusion that meta-epistemological concerns are the central issues in the discipline of epistemology.

2.2 Normative Epistemology. Normative epistemology7 is a less distinct area, but there are a number of items that are specific to it. Like the normative ethicist, the normative epistemologist assumes that there is a solution to skeptical objections and proceeds to articulate what constitutes the correct basis of knowledge. As Brandt puts it: "[Normative epistemologist] ... have attempted to arrive at acceptable universal epistemological statements to be used as standards in appraising particular statements." (p. 6) While meta-epistemology is concerned with the role that "justified belief" plays in the analysis of the concept of knowledge, normative epistemology is concerned to articulate the epistemological norms which delineate what kind and quantity of evidence one needs to have a "justified belief.",

Here one finds the traditional debate between the rationalist and intuitionists on one side, and the empiricists and naturalist on the other side of a debate which parallels that of the Kantian and the Utilitarian. These various epistemological views have even had the same geographic orientation as we saw in the ethical debate in which Europeans prefer rationalism and intuitionism (and Kantianism) and the Anglo/Americans prefer empiricism and naturalism (and Utilitarianism).

Work in the philosophy of science (and its sub-areas) seems to occupy a middleground: partly normative epistemology, partly applied epistemology. Grounded as it currently is in the actual practice of scientists it seems to reside naturally in applied 
epistemology, but its origins are in the efforts of both rationalists and empiricists to discover a basis for science without trying to ground it in the actual methods used by scientists. There is, for example something wonderfully rationalistic about Mill's methods which is little troubled by actual scientific activity. Recently the philosophy of science has emphasized more attention to the actual way the scientist assess claims which is more analogous to what goes on in applied ethics and, thus, closer to applied epistemology.

2.3 Applied Epistemology. I see applied epistemology as first attempting to apply the insights of normative epistemology to the everyday pursuit of knowledge. This activity involves using normative epistemological views (for example, the role that the elimination of competing hypothesis plays in defending a causal claim in the basis of scientific knowledge), much more than "logical principles." In teaching Critical Thinking we are, among other things, promulgating epistemological norms. And I think we find ourselves in a somewhat happier situation than those who first set out to apply normative ethics.

By describing, for example, the role that the elimination of competing hypotheses plays, we can illuminate for our students important facts about the way scientists acquire knowledge and give them useful rules of thumb for assessing everyday causal claims. The well established distinction between questions of how scientific discoveries are made and how they are established has many useful parallels in everyday life.

As indicated, much of the progress in philosophy of science has resulted from actually attending to how scientists arrive at their knowledge of the world. It has produced support for relativism (the recognition that scientific world views are grounded in the culture(s) of science), but at the same time, has yielded insights which have influenced working scientist (cf. those scientist influenced by Karl Popper). These later insights are on the border line of normative/ applied epistemology.

Hume's attempt to show that miracle claims can be dismissed a priori is a nice, though controversial, example of trying to do applied epistemology. Similar efforts to apply epistemology are often made in the magazine, The Skeptical Inquirer. This magazine while often concerned with the straightforward factual refutation of paranormal claims, also focuses on epistemological considerations such as the question of whether the claim is falsifiable. These are examples of using our epistemological understanding to illuminate and criticize dubious, everyday knowledge claims, and parallels the attempt to apply ethical principles to contemporary issues in applied ethics.

The final parallel that I wish to emphasize is that between doing applied epistemology and applying epistemology. In applied ethics, for example, we deal with abortion in general; in applying ethics we decide on the rightness of a particular abortion. By analogy in applied epistemology we might deal with questions concerning role that the elimination of competing hypotheses plays in establishing a causal claim, but not the question of whether this or that particular hypothesis should be, or has been, eliminated. On the other hand, as with applied ethics, the criticism of a particular view on epistemological as opposed to factual basis is a legitimate activity within applied epistemology. ${ }^{8}$

But my concern is not simply to draw the parallel between critical thinking and applied epistemology, but to use this analogy to support the claim that the concerns of critical thinkers have significant philosophical import. In particular the efforts to apply epistemological understanding to practical problems uncovers a number of difficulties within epistemology.

\section{Some Implications for Normative Epistemology}

For example, one of the most obvious 
facts about how knowledge is actually acquired is the heavy reliance on authority. Most of what we know, we know because someone told us. This is out of line with the traditional emphasis on either reason or experience as the basis of knowledge. What is the state of the theory of appeal to authority? It hardly exists. ${ }^{9}$

But there other even deeper problems. While great effort is expended on trying to decide what else there is to knowledge besides justified true belief, little time is spent on what would count as sufficient justification for a belief to be the basis of a knowledge claim. The assumption may be that there is little in general that can be said about the rules which would specify what evidence would constitute sufficient justification for a belief to be the basis of a knowledge claim: that this question must be answered by probability theory or intradiscipline norms. But, of course, it is just such a question that presents itself to us every day, and such questions do not always fall into some discipline's "jurisdiction." "Do I have enough evidence to proceed with this injunction, business decision, complaint...etc? Can I say "I know" he did it on the basis of the evidence that I have?"

A related issue arises when considering people's actual willingness to make knowledge claims. Our willingness to claim we know something seems to be, at least partly, a function of what is at stake: weaker justification being sufficient for issues of lesser importance. I may say that "I know you are coming at five" simply on the basis of overhearing you say so, until I discover that my life depends on my being right. This point is related to Austin's insight that claiming to know was a kind of performative. (Austin, 1979) But Austin's claim is a descriptive claim, a meta-epistemological claim. The question applied epistemology would treat would be: when is it reasonable to stake yourself behind your claim, to claim that you know?

These are crucial epistemological questions. Questions that should have been ad- dressed by philosophers, and questions that get much impetus when one attempts to apply epistemology to issues of everyday concern. These problems seem to me rich enough to justify the creation of a new field. Before we can advance the teaching of critical thinking beyond the largely introductory nature of current courses, these questions require deep, theoretical study.

\section{Examples of Applied Epistemology}

There may not appear to be as many clear examples of the need for applied epistemology as there are examples of the kind of practical problems that requires applied ethics: medicine, in particular, seems to supply enough moral problems to keep a legion of applied philosophers employed. But we really need not look far to find analogues for the applied epistemologist. Law is one obvious profession where putative factual claims are made and assessed in light of implicit and explicit epistemological norms. Much use is made, for example, of the fact/opinion distinction which Perry Weddle has shown to be fraught with difficulty. (1985)

Decision theory too, to the extent that it involves considerations of rational belief as a basis for action, also involves issues in applied epistemology, For example, the issue of the appropriate 2 nd order decision principle to apply (Type I or Type II) to the question of whether to believe a claim on the basis of evidence that is too weak to support a knowledge claim is a question for applied epistemology. A lovely example of such the application of just such principals can be found in William James' famous article "The Will to Believe" (1896).

An excellent example of a text that takes critical thinking beyond basic instruction is Ronald Giere's book, Understanding Scientific Reasoning. He elaborates a fairly sophisticated view about the basis of scientific knowledge, and attempts, in a simplified but theoretical way, to explain 
to people how to apply this approach to (1) theories in the natural sciences such as physics, (2) theories in the more statistically based sciences such as epidemiology and sociology, and (3) popular theories such as Danekin's Chariot of the Gods. This is a highly commendable enterprise and because of its explicit theoretical base his work is superior to other works such as Science and Unreason which are more superficial.

In my view, and perhaps Giere's current view, there is too little emphasis on the role that the scientific community plays in assessing and establishing scientific knowledge. But whatever the difficulties with his particular approach, the students do learn a great deal from this careful and largely non-mathematical approach to science. They develop quite clear procedures for assessing statistical information and good reasons to dismiss popular mythology like Danekin's. The difficulties and problems are grist for the applied epistemologist.

Another nice example of applied epistemology is one I have already alluded to: Hume's attack on miracles. ${ }^{10}$ Hume argues that no empirical evidence or testimony could be sufficient to overwhelm the essential improbability of any claimed miracle. He also offers much historical evidence about people's misguided enthusiasms for the miraculous and extraordinary. But his argument against the possibility of justifying claims of the miraculous on the basis of fundamental epistemological considerations is an exemplary instance of applied epistemology. This is not to say that his argument is uncontroversial; it is not an algorithmic application of well established epistemological norms, but rather an argument which focuses on a particular set of judgements and, using epistemological reflections, supports a sceptical position on claims on this type.

Another instance of applying epistemological reflections would be to consider the use of the standards of statistical significance, especially in the various social sciences. Statisticians have fixed on the ssd.05 as the minimal standard for a 'scientific' knowledge claim. To make this pint I need to supply a bit of background. The basic issue is how to decide the significance of statistics gathered by sampling. We have all read that Gallup polls typically allow for a confidence interval of $\pm 3 \%$ (19 times out of 20). This means that Gallup is claiming that the percentage of the whole population holding a certain view will be within $\pm 3 \%$ of whatever percentage Gallup's poll yielded, 19 times out of 20 (i.e. $95 \%$ of the time). We can than say that we know (or at least that we are justified in believing) that the range in the population is $\mathrm{X} \pm 3 \%$. We can say this, because the $95 \%$ rule has been adopted as the norm of statistical significance for most statistical purposes. Introductory statistics students, for example, are taught that in the typical Gallup poll, changes in a politician's popularity are (statistically) significant only if they exceed $\pm 3 \%$. But is this the appropriate criterion? Why are we not prepared to say that while there is a $95 \%$ chance of the population being distributed within $\pm 3 \%$ of Gallup's results, there is, say, a $75 \%$ chance of it being within $1 \%$. After all, how many things in life are $95 \%$ certain? Must all our knowledge claims (significance claims) meet a $95 \%$ certainty criteria? My goal is not to answer this question but to offer it as another illustration of the kind of epistemological claims that are not necessarily addressed in any discipline and deserve philosophical reflection.

\section{Applied Epistemology and Other Aspects of Critical Thinking}

It must be admitted that much of what we typically teach in Critical Thinking classes is preliminary to the teaching of applied epistemology, and as a result the concept and curriculum of Critical Thinking embraces a much broader range of skills and 
norms than are involved in applied epistemology. We must, of course, teach analysis of argument before we teach assessment and with some students this is a significant task. If students cannot recognize deductive inferences and their significance, then this, too, must be taught. But we teach analysis in order to teach assessment, so it seems fair to treat applied epistemology as the core discipline of Critical Thinking instruction.

In addition, there are activities associated with Critical Thinking that are neither evaluation or analysis, such as problem solving, creative thinking, argumentation theory, and for some, even ethical analysis. Almost all practitioners also consider the inculcation of the disposition to be reasonable as an important component of any Critical Thinking course. None of these topics are obviously epistemology, applied or otherwise, though it seems to me again that they are all directed at teaching students to apply appropriate epistemological norms in their lives. The purpose of creative thinking (lateral thinking, etc.) is surely to help people out of habitual and incorrect beliefs into true or at least better justified beliefs.

On the other hand the temptation in many public schools to implement "creative thinking" as the central focus of Critical Thinking teaching seems, therefore, significantly wrong. And while this issue has been well treated in this journal, (cf. Sharon Bailin, 1987) arguing for the centrality of applied epistemology is a healthy correction to those tendencies.

\section{Summary}

These remarks are somewhat speculative, but they suggest some of the possibilities that flow from a study of applied epistemology-even the possibilities of theoretical developments in normative epistemology. The view of critical thinking as applied epistemology ties it to its proper theoretical discipline, and encourages the possibilities of a two way relationship between the theoretical and practical sides of the discipline, an approach which will be of benefit to both. If this is true, we have much fascinating and exciting work ahead. And, (almost) needless to say, a great deal of teaching to do. We must not only help our students to improve their Critical Thinking, but also help our colleagues see the significance of critical thinking/applied epistemology as a philosophical discipline. ${ }^{11}$

\section{Notes}

1 'critical thinking' is a more generally used term for the subject I wish to discuss, but 'informal logic' is the term more widely used in philosophical circles-indeed, as the name of this journal. While the terms are often used in terchangeably I think it should be noted that for most educators informal logic (the analysis and evaluation of arguments in ordinary discourse) is a subset of critical thinking. Critical thinking is often taken to involve not only argument analysis and evaluation, but also creative thinking and problem solving skills and a positive attitude towards open-mindedness and the application of informal logic and problem solving skills in every day life. In its most full blown articulation, critical thinking can be viewed as an educational ideal very similar to the tradi- tional liberal arts ideal of the thoughtful citizen. In this paper I am concerned to focus on that aspect of Critical Thinking that is of central interest to philosophers-i.e. informal logic, not only because it is of interest to philosophers, but because it is the central concept on which the notion of Critical Thinking depends. Because I am recommending a change of terminology, the terminological problem becomes complex. For this reason I will use 'Critical Thinking' (capital ' $C$ ', capital ' $T$ ') to refer to Critical Thinking in its broadest ambit and 'critical thinking' without capitals as synonymous with 'informal logic'. In the long run I would recommend replacing 'informal logic' with 'applied epistemology', and keep 'critical thinking' (with or without capitals) to 
include the broader range of concerns.

2 I thought this claim was unproblematic, but a commentator on my paper objected. In support I quote the following statement from William Frankena's classic introduction to ethics:

[Meta-ethics] asks and tries to answer logical, epistemological, or semantical questions like the following: What is the meaning or use of the expressions "'(morally) right"' or ' 'good:'? How can ethical and value judgements be established or justified. Can they be justified at all? What is the nature of morality? What is the distinction between the moral and the nonmoral? (Frankena, p. 5, also see p. 96 and Brandt, p. 7)

3 Rawls, A Theory of Justice. He also does quite a bit of applied ethics in this text.

4 This is a reference of course to the insightful article by J. J. Thompson, "A Defense of Abortion."

5 A commentator on an earlier version of my paper brought to my attention an article by Richard Brandt in the Encyclopedia of Philosophy that draws similar parallels between meta-ethics and what he, too, calls metaepistemology, and normative ethics and epistemology, though he makes no mention of applied ethics and, needless-to-say, no mention of applied epistemology.

6 Hans Hansen has brought to my attention a 1982 paper by William $P$. Alston which makes the same point:

Recent epistemology has been heavily concerned with the conceptual and methodological foundations of the subject-in particular with the concepts of knowledge, certainty, basic knowledge, justification, and so on. In other words to a considerable extent it has been taken up with meta-epistemology, in contrast with substantive epistemology, in contrast with questions about what we know, how we know it, and how various parts of our knowledge are interrelated.
Just as with ethics, meta-inquiries have been pursued throughout the history of the subject..., but also as in ethics, meta concerns have been more prominent in twentieth century Anglo-American philosophy than ever before. (Alston p. 275)

7 Alston characterizes this as "substantive epistemology," while Brandt describes it as “epistemology proper." (p. 6)

8 Harvey Siegel, in criticizing an earlier draft of this paper, argued that ethical questions such as "what should I do?" are answered by normative ethics, but that questions of "what should we believe?" are not answered by normative epistemology - hence my analogy was problematic. This seems to me to miss the complexity of both kinds of questions. Obviously factual considerations play a part in most ethical decisions and these are not the objects of ethical inquiry. Obviously also, observation, mathematics and formal logical inference plays a role in scientific investigation, and these are not the objects of epistemological reflection. But to the extent that a doctor is misapplying ethical norms or concepts (perhaps through inadequate justification) she is subject to ethical criticism and this could be justly done in a paper in applied ethics. Concomitantly, to the extent that a scientist is employing epistemological norms in supporting her claims, both the application and content of these norms could justly be questioned by epistemologists-applied or otherwise.

9 After I wrote this I read the article by John Hardwig which is an excellent first step to explicating the role that authority plays in scientific knowledge. Subsequently I have written a paper, "Assessing Expert Claims: Critical Thinking and the Appeal to Authority" which attempts to develop a theory of appeals to authority.

10 Hume, An Enquiry Concerning Human Understanding, Sections VIII-XI.

11 I wish to thank the following helpful readers and commentators: Diana Davidson, Harvey Siegel, Earl Winkler, Hans Hansen, and Reid Gilbert. 


\section{References}

Austin, J. L. (1979), "Other Minds" in Philosophical Papers (3rd ed.), Urmson, J. O., and Warnock, G. J. (eds.) Oxford: Oxford University Press. pp. 77-116.

Alston, William P. (1978), "Meta-Ethics and Meta-Epistemology." in Values and Morals, Goldman, A. I. and Kim, J. (eds.), Dordbrecht: D. Reidel Publishing, pp. 275-297.

Battersby, Mark (1988), “Assessing Expert Claims: Critical Thinking and the Appeal to Authority" in Proceedings Montclair College Conference on Critical Thinking, New Jersey: Montclair State College.

Bailin, Sharon (1987), "Creative and Critical Thinking." Informal Logic, vol. IX, no. 1, 1987, pp. 23-30.

Brandt, Richard (1967), "Epistemology and Ethics, Parallel Between"' in The Encyclopedia of Philosophy, Edwards, Paul, vol. 3, pp. 6-8, New York: Macmillan.

Frankena, William (1973), Ethics (2nd ed.). Englewood Cliffs, NJ: Prentice-Hall.

Giere, Ronald (1984), Understanding Scientific Reasoning (2nd ed.). New York: Holt, Winston, Rinehart.

Govier, Trudy (1987), Selected Issues in Logic and Communication. Belmont, CA: Wadsworth.

Hardwig, John (1985), "Epistemic Dependence." Journal of Philosophy, vol. 82, no. 7, pp. 335-349. A modified version appears in Govier, pp. 125-37.
Hume, David (1748), Enquiry Concerning Human Understanding. Many contemporary editions.

James, William (1896), The Will to Believe and Other Essays in Popular Philosophy. New York: Longmans, Green.

McPeck, John E. (1981), Critical Thinking and Education. Oxford: Martin Robertson.

Polanyi, Michael, and Harry Prosch (1975), Meaning. Chicago: University of Chicago Press.

Rawls, John (1971), A Theory of Justice. Cambridge, MA: Harvard University Press.

Siegel, Harvey S. (1985), "Educating Reason: Critical Thinking, Informal Logic and the Philosophy of Education." Informal Logic, vol. VII, 2 \& 3, pp. 69-83.

(1988), Educating Reason: Rationality, Critical Thinking, and Education. New York: Routledge.

Thomson, Judith J. (1971), "A Defense of Abortion," Philosophy and Public Affairs, vol. 1, pp. 47-64.

Weddle, Perry (1985), "Fact from Opinion," Informal Logic, vol. VII, no. 1, pp. 19-26. Also in Govier, pp. 55-64.

MARK BATTERSBY

CAPILANO COLLEGE

2055 PURCELL WAY

NORTH VANCOUVER

BRITISH COLUMBIA V7J 3 H5. 